\title{
Exit Polls, Turnout, and Bandwagon Voting: Evidence from a Natural Experiment
}

\author{
Rebecca B. Morton, Daniel Müller, Lionel Page, and Benno Torgler*
}

February 5, 2013

\begin{abstract}
We exploit a voting reform in France to estimate the causal effect of exit poll information on turnout and bandwagon voting. Before the change in legislation, individuals in some French overseas territories voted after the election result had already been made public via exit poll information from mainland France. We estimate that knowing the exit poll information decreases voter turnout by about 12 percentage points. Our study is the first clean empirical design outside of the laboratory to demonstrate the effect of such knowledge on voter turnout. Furthermore, we find that exit poll information significantly increases bandwagon voting; that is, voters who choose to turn out are more likely to vote for the expected winner.
\end{abstract}

*Morton: Department of Politics, New York University (e-mail: rebecca.morton@nyu.edu). Müller and Page: School of Economics and Finance, Queensland University of Technology and QuBE (e-mail: d3.mueller@qut.edu.au and lionel.page@qut.edu.au). Torgler: School of Economics and Finance, Queensland University of Technology and EBS Business School, ISBS, EBS Universität für Wirtschaft und Recht and CREMA - Center for Research in Economics, Management and the Arts and QuBE (e-mail: benno.torgler@qut.edu.au). We thank Pauline Grosjean, Arye Hillman, Björn Kauder, Jeffrey M. Wooldridge and participants of the 5th Australasian Public Choice Conference for helpful discussions and Malka Guillot for excellent research assistance. 


\section{Introduction}

"A Californian plans to vote after work in what she believes to be a close presidential election. (She has little interest in the race for congressman for her district, although it is closer.) The day is rainy and as she approaches the polling place she sees a long line. On the radio she hears that one presidential candidate has a substantial lead in other states. She says why bother and turns her car around and drives home."

Sudman (1986, p. 332)

In August, 2009, exit poll results for key regional elections in Germany were leaked on Twitter before voting ended. These polls showed that Chancellor Angela Merkel's conservative party had much less support than in previous elections. Wolfgang Bosbach, deputy parliamentary head of Merkel's Christian Union bloc, said that the leaked results "damaged democracy" and a spokesman for the pro-business Free Democrats, Merkel's preferred coalition partner, commented that the leaks were "unacceptable." In addition, such reporting is against the German law with a fine of up to 50,000 euros, so German election officials immediately began to investigate whether the Twitter messages violated the law 1 The German case is not unusual: a survey of 66 countries worldwide finds that of the 59 that permit exit polls during an election, 41 prohibit publication of the results until after all voting has concluded (see Spangenberg (2003)).

Yet in recent 21st century elections, incidents similar to the 2009 Twitter controversy in Germany abound. In 2007, the websites of several Swiss and Belgium newspapers crashed when French citizens attempted to access exit poll results during an election and in the 2012 French presidential election, results were also available online while voting was still in progress ${ }^{2}$ Countries with multiple time zones like France, the United States, Canada or Russia, in which

\footnotetext{
${ }^{1}$ See Carter (2009).

${ }^{2}$ See Sayare (2012).
} 
voting takes place at different times in different regions face particular difficulties 3 The notorious reporting on Floridian exit poll results in the 2000 United States presidential election occurred while voters in the western part of the state and the rest of the nation were still voting. In 2004 leaked US presidential exit poll results were commonly discussed among voters while east coast voters were still going to the ballot booths $A^{4}$ With the proliferation of Twitter, Facebook, and other social media worldwide, the ability of governments to control and limit leaked exit polls both inside and outside their countries is becoming increasingly difficult.

Despite the growing tendency for voters to learn exit polls results while an election is still ongoing, observational data-based research on the effects of such information on voting behavior is limited and inconclusive. One possible natural setting for exploring this issue is the so-called West Coast effect in the U.S.; that is, the release of early East Coast election returns before the polls close on the West Coast due to the fact that the presidential election takes place in three different continental time zones. The debate over this effect emerged in the early 1960s after the introduction of sophisticated computer models, improved survey techniques for predicting election results, and rapid access to media information. The first set of related studies, however, which explored the 1964 presidential election, showed barely any West Coast effect (see for example McAllister and Studlar (1991)).

A second set of major studies focused on the 1980 election 5 in which preelection polls indicated a close election between Reagan and Carter, but Carter

\footnotetext{
${ }^{3}$ The United States does not prohibit the reporting of exit poll results, so elections are often publicly decided before voters in Alaska and Hawaii have voted, and sometimes while voting in California and other western states is still ongoing. In Canada polls close at the same time across the country to reduce the potential of leaked results. In India, although the country is not subject to the same time zone issues, voting is conducted at different times in different regions for security reasons and reporting early results is illegal.

${ }^{4}$ See Best and Krueger (2012) for a review.

${ }^{5}$ It should be noted that other elections between 1964 and 1980 have also been explicitly analyzed. For example, Tuchman and Coffin (1971) explore the influence of election night television broadcasts on the close 1968 election but find no evidence that it affected voting.
} 
conceded defeat even before the polls closed in the west ${ }^{6}$ However, although these researchers used a richer set of data (aggregated data on various elections, regional, data or congressional districts, or better survey data), they produced mixed results. For example, Jackson (1983), using a pool of 1981 persons interviewed before and after the election, found some evidence that media coverage of exit polls in the 1980 U.S. presidential election did lead to a reduction in turnout. However, the survey data used in his and a number of similar studies of the 2000 election have been strongly criticized as unreliable (see the review in Frankovic (2001)7 .

Despite this lack of conclusive observational evidence on exit polls' effects on subsequent voter choices, however, a few laboratory studies, do suggest that information about early voting can have significant effects on voter behavior. These studies indicate that later voters' choices appear to be influenced by information about early voting. More specifically, later voters with the same preferences who have learned early voter choices make different turnout decisions (see Battaglini, Morton, and Palfrey (2007)) or vote for different candidates (see Hung and Plott (2001), Morton and Williams (1999) and Morton and Williams (2001)) than they would have done without that information.

If, as the experimental evidence suggests, later voters are indeed so influenced by early voting results, then the advent of increasing social media reports

\footnotetext{
${ }^{6} \mathrm{NBC}$ was also strongly criticized for declaring Ronald Reagan the President of the United States at 8:15PM eastern standard time based on its own computer projections: "Articles, reports, and letters were written describing how voting lines outside polling places disappeared, how turnout decreased over prior years, and how voters stayed home after it became apparent that their favored candidates had already won or lost" (Leonardo (1983, p. 297)). Criticism also emerged that national voter turnout decreased to $53.95 \%$ (the rate since 1948 , see Dubois (1983)). All this criticism led to a congressional hearing, journalistic commentary, private studies, and a task force report, as well as the proposition of remedial bills to regulate either poll closing times or the timing of network election predictions, but no action was taken once interest began disappearing (Leonardo (1983), Carpini (1984)).

${ }^{7}$ Frankovic, Kathleen, "Part Three: Historical Perspective," in Linda Mason, Kathleen Frankovic, and Kathleen Hall Jamieson, CBS News Coverage of Election Night 2000: Investigation, Analysis, Recommendations, January 2001.
} 
of election results through exit polls can lead to fundamental changes in the way voters behave. It may thus have important consequences for how democracy works in many countries. Most obviously, candidates and political parties may have incentives to manipulate the reported results in order to seek advantages. But even if the results are accurately reported, other serious effects might occur. For example, if later voters are less likely to participate or have a tendency to engage in bandwagon voting, then the candidates preferred by earlier voters may be more likely to win elections. To the extent that the timing of the voter participation decision is exogenous and depends on voter characteristics such as income, ethnicity or other factors that arguably affect voter preferences, then voters may be unequally represented even though their votes are theoretically equal. At the same time, to the extent that the timing of voting is endogenous, candidates and political parties will have an incentive to engage in strategic manipulation of the factors that influence when individuals choose to participate, much like the strategic manipulation in the timing of presidential primaries in the United States 8 Hence, given that the election process is fundamentally changing with social media reporting of exit poll results, whether later voters' choices are influenced is an important empirical question for many countries in which such information has historically not been available 9

In this paper, we make use of a unique natural experiment to address the question whether later voters behavior is affected by exit poll information about earlier voter choices. Specifically, we exploit a 2005 voting reform in France to estimate the causal effect of exit poll information on turnout and bandwagon (or underdog) voting. Before the change in legislation, individuals in French western overseas territories voted after the mainland election results were already known via exit polls. This reform creates an exogenous variation in information for a well identified group of voters and provides therefore the setting for a natural experiment to study the effect of exit poll information on voters behavior.

\footnotetext{
${ }^{8}$ See Morton and Williams (1999) for a discussion of these manipulations.

9 Thompson (2004) presents additional normative and philosophical arguments against the revelation of such information to later voters.
} 
Such an approach has two advantages. First, relative to existing studies on the West Coast effect, our natural experimental setting allows us to eliminate lots of the possible caveats in the analysis of the causal effect of information by providing a counterfactual situation (same constituencies with and without exit poll information). Second, our study does not suffer for the possible concern about the ecological validity of the results, a criticism often raised about laboratory experiments.

Using this voting reform to study the effect of exit poll information, we find evidence that the public knowledge about such polls not only decreases turnout by about 10 percentage points, but also increases bandwagon voting. We therefore conclude that exit polls can indeed have consequential effects on voter behavior and that the advent of social media reporting on exit poll information may fundamentally change the democratic process in many countries where such information was previously unavailable.

In the next section, we review the relevant theoretical literature on information and voting behavior. Section 3 then outlines our empirical research design and the natural experiment, Section 4 presents our results regarding the effect on turnout, Section 5 addresses robustness concerns and Section 6 presents the results on the Bandwagon effect. We conclude and discuss the implications of our analysis in Section 7 .

\section{The Role of Exit Poll Information in Voting Choices: Theory and Experimental Evidence}

When individuals know the results from earlier voting as in leaked exit polls, voting becomes sequential in nature. In the case of complete information about the choices before voters but incomplete information about other participants' preferences, learning the results of earlier decisions simply provides later participants with information about the likelihood that their vote may be pivotal. It is thus straightforward to show that if voting is costly (even if the costs are 
minimal), learning that one's own decision will not affect the outcome implies that a rational individual should abstain. If however, a voter learns instead that the election is extremely close and the probability of being pivotal is high, then later voters may actually participate at greater rates than they would if voting were simultaneous and they had less precise information about other voter's choices.

If voters have private information about the choices before them in an election, then early voting results not only reveal the extent to which individual choice may be pivotal but may also provide later voters with insights into the information held by early voters about the choices. As shown by Battaglini (2005), when voting is costly the set of equilibria in sequential private information voting games are disjoint from those in which voting is simultaneous. That is, later voters' choices will be influenced by the results of early voting. Battaglini, Morton, and Palfrey (2007) also find support for these qualitative theoretical predictions in laboratory elections using a three-voter game; in particular, they find significant evidence of strategic abstention by later voters. Other results, however, are at variance with theory - they find that early voters tend to participate more than theoretically predicted, whereas later voters abstain more, sometimes even when their votes could be pivotal. They conclude that, as predicted, although sequential voting tends to be more informationally and economically efficient than simultaneous voting, later voters benefit at the expense of early voters, so there is a cost in terms of equity. Nevertheless, they find no evidence of later voters ignoring their private information and engaging in bandwagon or underdog voting.

Callander (2007) considers the comparison of simultaneous and sequential voting under asymmetric information when voters receive utility from conforming to the majority (voting for the winner) independent of the utility they derive from whether the winner is their own best choice. Specifically, he derives an equilibrium under sequential voting in which voters engage in bandwagon voting (voting for the leading candidate) even though their private information may suggest that the leading candidate is not their own best choice. He finds 
that such bandwagon voting may occur even when later voters' choices are not pivotal and the outcome is already decided (because of the additional utility voters receive from the act of voting for the winning candidate). This argument is supported by earlier work by Hung and Plott (2001), which provides experimental evidence of conformity voting when subjects are rewarded for doing so. Presumably, if voters similarly receive utility from voting for an underdog candidate (or are rewarded for doing so in an experiment), then later voters may also engage in underdog voting even when they previously believed the leading candidate to be their own best choice.

Hence, both theory and the experimental evidence suggests that if the act of voting is costly, when later voters learn from exit poll information that their decision is unlikely to be pivotal, they are more likely to abstain. If, however, they receive utility from the act of voting for either the winner or the underdog (independent of whether the winner is their own best choice), then such exit poll information may lead them to engage in either bandwagon or underdog voting, respectively.

Our natural experiment allows us to evaluate the extent to which exit poll information affects the turnout of later voters and whether later voters are more likely to engage in either bandwagon or underdog voting.

\section{The Natural Experiment: Institutional Back- ground and Empirical Strategy}

\subsection{The French Electoral System}

France is one of the few countries in Europe to have a presidential system. The French president is directly elected by the citizens via a two-round runoff system. In the first round a large number of candidates can participate ${ }^{10}$ If one candidate receives more than $50 \%$ of the votes in the first round he

\footnotetext{
${ }^{10}$ To be eligible to run, a candidate must gather 500 signatures from local politicians such as town councilors.
} 
or she is declared the winner. Such an immediate victory, however, has only happened once since the beginning of the Fifth Republic, in 1958 ${ }^{11}$ Usually, the two candidates that receive the most votes participate in a second round to determine the winner.

This two-round runoff system model is also used in most other elections in France with some variation. The French parliamentary elections differ slightly in the sense that the two-round runoff elections within each constituency allow more than two candidates to participate in the second round ${ }^{12}$ In practice, however, although a few second rounds are disputed by three candidates, most involve only two.

Balloting traditionally takes place on a Sunday. French electoral law prohibits exit poll publication until the close of voting in mainland France (Bale (2002)) and bans publication, broadcasting and commenting on opinion polls for the day before and the day of the election (Saturday and Sunday). The electoral law also stipulates that the official campaign has to stop for these last two days ${ }^{13}$

When a French presidential election is held, it is always the only contest on the ballot, which stands in contrast to, for example, U.S. elections, in which ballots include local, congressional and senatorial posts, and even local propositions and initiatives. The French case thus allows us to measure turnout for presidential elections only, meaning that the turnout measured is not confounded by effects from other elections.

During the day of the election, the release of exit polls is therefore not allowed

\footnotetext{
${ }^{11}$ This presidential election was the first one of the Fifth Republic. De Gaulle had overseen the design of the new constitution and was seen as having saved France from a potential military coup by the many army generals opposed to the process of Algerian independence. In these dramatic circumstances, De Gaulle won the election with more than $78 \%$ of the votes. ${ }^{12}$ In order to participate in the second round, candidates must gather a minimum proportion of registered voters in the constituency, currently $12.5 \%$. In presidential elections, however, there are always exactly two candidates in the second round.

${ }^{13}$ The law was initially voted in in 1977. At that time, the publication and broadcasting of opinion polls were banned for one week before each of the two rounds of voting. It was changed in 2002 to limit this interdiction to the last two days before the results.
} 
until after the closure of the last polling booth in mainland France, on Sunday at 8:00PM CET ${ }^{14}$ At exactly 8:00PM, TV channels release highly precise early estimations of the final results. These are based on large exit polls and on the first results from the majority of polling booths, which close at 6:00PM

To demonstrate the quality of these early estimates, we collected the 8:00PM CET forecasts for each candidate from the main public channel (France 2) at every election in our sample. Table 1 lists these forecasts, together with the actual results and the differences between the two. In the second round of the 1981 election, for example, the difference between the final result and the 8:00PM predictions is the same for both the first candidate and the runnerup at 0.06 percentage points, with the forecasted difference between the two candidates at $3.4 \%$ and the actual difference at $3.52 \%$. As Table 1 clearly shows, exit poll forecasts are extremely accurate, the final ranking is always the one predicted by the forecast and the vote shares are most often similar to a few decimal points.

\footnotetext{
${ }^{14}$ Central European time (CET) is used in most parts of the European Union and is one hour ahead of Coordinated Universal Time (UTC). Polling booths in main urban areas close at 8:00PM while most polling booths in the countryside close at 6:00PM.

${ }^{15}$ Given that all votes are aggregated at the national level, the law of large numbers helps these estimations to be precise. Unlike the case in the UK or U.S., the result does not depend on some swing constituencies/states from which the final result can take time to emerge. In fact, the final difference between early estimations and the final official results is typically less than 0.3 percentage points for any given candidate, see Table 1
} 


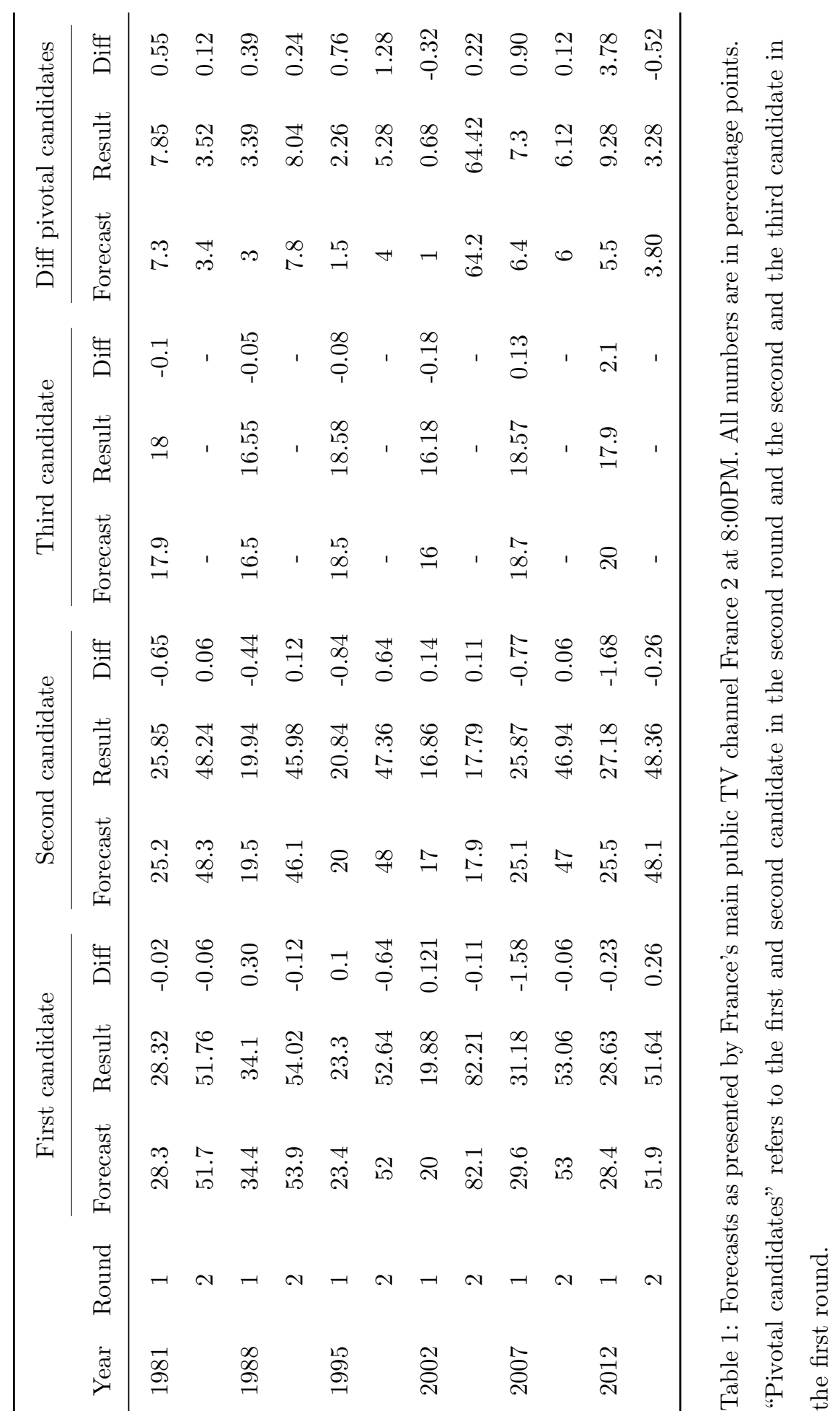




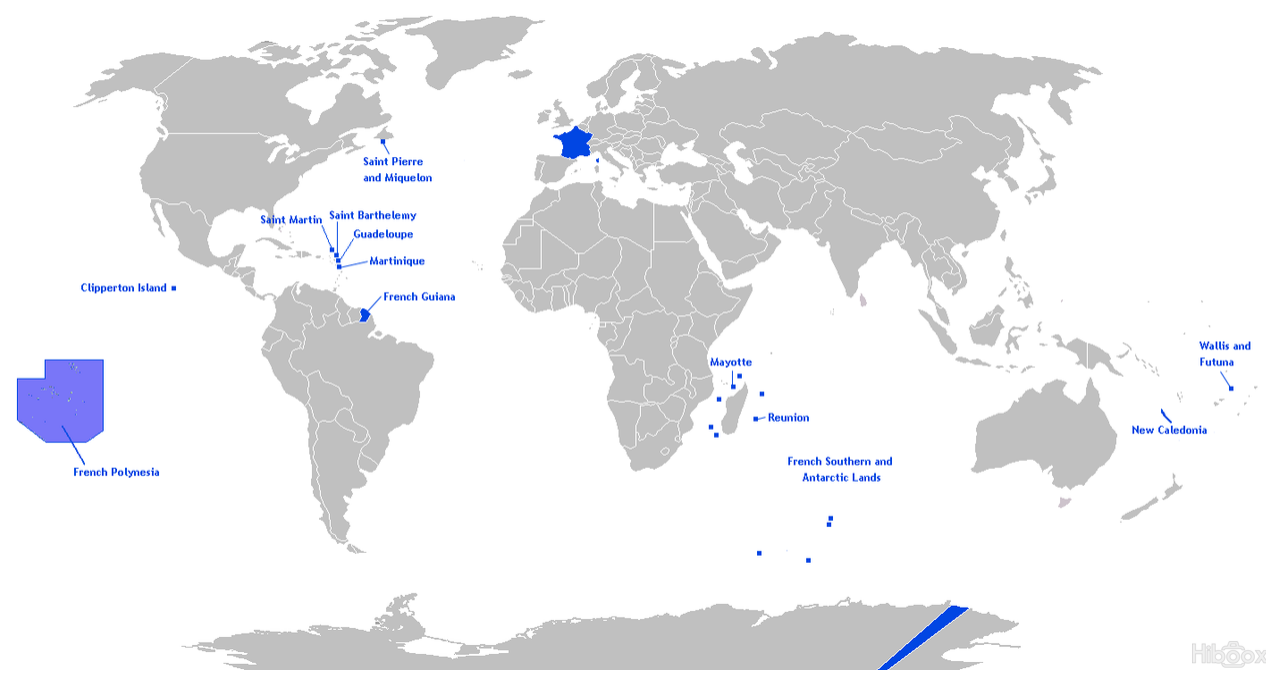

Figure 1: France and its overseas territories, taken from Wikipedia.com.

\subsection{The 2005 Electoral Reform}

Figure 1 provides a map of France and its overseas territories (hereafter OST or DOM-TOM), which are spread across the globe with time differences ranging from +12 hours UTC ${ }^{16}$ (Wallis and Futuna) to -10 hours UTC (French Polynesia). People living in the OST are fully fledged citizens of the French Republic and therefore participate in the French presidential election in the same way as French citizens on the mainland 17

Before 2005, French elections were held on Sundays in every territory (mainland and OSTs), meaning that they began in the most eastern parts, New

\footnotetext{
${ }^{16}$ Coordinated Universal Time (UTC) is the international time standard. It closely resembles the "Greenwich Mean Time" with the latter being outdated.

${ }^{17}$ The OST are divided in two categories: overseas departments (DOM) whose laws are identical to mainland France, and overseas territories (TOM) which are granted sufficient autonomy for local laws to differ from mainland France. French OST status and its relationship with mainland France changes from time to time. For example, New Caledonia is an overseas territory that is expected to vote on an independence referendum over the next few years. Conversely, Mayotte, an island in the Comoros archipelagos, recently voted by referendum to abandon TOM status and become a DOM, making it a new French department with the same laws and regulations as mainland France.
} 
Caledonia, Wallis and Futuna, and then moved progressively across the more westerly territories as the opening time for polling booths arrived (typically between 8:00AM and 9:00AM). As a result, the territories located to the west of the French mainland (e.g. the Caribbean, Guiana) and in the Pacific (French Polynesia) voted partially or completely after mainland France.

Because the mainland accounts for approximately $96 \%$ of the total French population ${ }^{18}$ in national ballots like presidential elections, the result on the mainland almost certainly determines the overall election result. This setting is therefore different from that of the U.S., where the number of electoral votes determined by California can empirically decide the outcome of a close contest.

Table 1 shows that in most cases the result is fully determined once the mainland results are known. Voters in overseas territories west of mainland France only represent around $1.5 \%$ of the French electorate. The predicted difference between the two "pivotal candidates" (the first versus the runner-up in the second round and the second versus the third candidate in the first round) given by exit polls is almost always below $1.5 \%$.

To illustrate this point further, Table 2 shows the number of votes by which the runner-up was ahead of the third candidate in mainland France in the first round and the voting edge of the first versus the second candidate in the second round, respectively. It also gives the number of registered voters in the western OSTs and the corresponding difference between both measures for each election in our sample. As is apparent, in only two elections would it have been mathematically possible for the western OST to make a difference: the first rounds of 1995 and 2002. In 1995, the difference is so large that changing the result would have required at least $95 \%$ of the registered voters in the west to vote for the third candidate and the remaining $5 \%$ not to vote for the second candidate. Such a scenario seems extremely unlikely. Moreover, in this election, both candidates were moderate conservatives, giving limited incentives for voters to try and change the outcome. The case is somewhat different, however, for the first round of 2002. Here if the difference between the second and third candidates

\footnotetext{
${ }^{18} 2.7$ million citizens in the OST versus 63.1 million in mainland France.
} 


\begin{tabular}{ccccc}
\hline \hline Year & Round & $\begin{array}{c}\text { Voting Edge on the } \\
\text { mainland }\end{array}$ & $\begin{array}{c}\text { Registered Voters in the } \\
\text { Western OST }\end{array}$ & Difference \\
\hline \multirow{2}{*}{1981} & 1 & 2,293 & 470 & 1,822 \\
& 2 & 1,247 & 470 & 776 \\
1988 & 1 & 995 & 556 & 439 \\
& 2 & 2,405 & 556 & 1,849 \\
1995 & 1 & 644 & 675 & -30 \\
& 2 & 1,486 & 675 & 810 \\
2002 & 1 & 254 & 756 & -502 \\
& 2 & 19,605 & 754 & 18,851 \\
2007 & 1 & 2,520 & 826 & 1,694 \\
& 2 & 2,200 & 826 & 1,374 \\
2012 & 1 & 3,232 & 869 & 2,363 \\
& 2 & 1,027 & 870 & 157 \\
\hline \hline
\end{tabular}

Table 2: Vote differences between the two pivotal candidates (2nd versus 3rd in first round, 1st versus 2nd in second round) on the mainland and in the east compared to the number of registered voters in the western OST. Numbers are in 1,000 votes.

in OST voting was approximately $33 \%$ of registered voters, then the outcome of the election would be affected by choices made in the OST. Although such a figure still seems quite unlikely, it is at least not completely impossible with evident consequences for voter turnout. In Section 5 , therefore, we conduct robustness checks to show that our estimates remain unchanged by this event.

As a result of this geographical distribution, before 2005 voters in the territories to the west of mainland France had access to information about the presidential election results while voting booths were still open, while French Polynesia and the territories off the American continent had precise information on election results by 9:00AM and 2:00PM, respectively. Hence, most 
voters probably knew who would win the election before voting. In fact, in 2002, the defeated presidential candidate Lionel Jospin resigned from his office before people in the western OST had even voted.

This situation was in conflict with the country's tradition of ensuring that voting days are free of campaigning and polls in order to allow every citizen to vote with the same information. Hence, in 2005, the voting order was changed. All the territories to the west of mainland France had their voting day changed to Saturday and became the first, instead of the last, territories to vote. The territories affected by this change were French Polynesia, St. Pierre and Miquelon, Guadeloupe, French Guiana and Martinique.

\subsection{Other Reforms and Relevant Events}

Any analysis of the effect of a policy change over a given period needs to ensure that the observed changes in the variable of interest cannot be explained by other policy changes or events happening during the same period. In our case, four potentially relevant events happened over the period studied that warrant discussion. First, in 2002, the duration of the presidential mandate was reduced from seven to five years, which may have affected the overall turnout at the national level. There seems to be no reason, however, why it should affect turnout differently in the OST relative to the mainland, and it is a priori even less likely that it would affect turnout differently in the OST to the west and east of mainland France.

Second, 2002 saw the first candidate from an OST (Guiana) participating in the first round of the presidential election, which could have led to a higher turnout in Guiana in this specific election. We control for this concern by including a dummy variable indicating Guiana in the first round of 2002 in the estimations (see Section 5.1).

Third, 2002 was also the first year in which a candidate from the far-right reached the second round, a totally unexpected event that created a political shock in the country. As the majority of the population in the overseas territories 
are not ethnically White, they are likely to be averse to this party's political objectives. We address this concern more closely in Section 5.2 we find no empirical evidence that this event affects our conclusions.

Finally, the last decade has seen the growth of the Internet, making access to information easier. Hence, in practice, early estimations of the election results are produced by polling companies as early as 5:00PM CET on the day of the election. In the 1980s, the laws preventing publication of early polls were easy to uphold because the only media able to report such early results would be punished severely for doing so. More recently, however, Belgian and Swiss newspapers have begun posting early estimations on their websites during election day but as they are based outside of France, even though French speaking, they are not bound to respect French electoral law. Unlike the early 2000s when access to the Internet was limited, by the 2007 and 2012 elections the spread of online election result information after 5:00PM had grown substantially, leading to a debate about the usefulness of a law which could be barely enforced. We allow for nonlinear time trends in our estimations to control for such changes over time.

\subsection{Data}

Our primary data set comprises French presidential election results, especially turnout for first and second election rounds from 1981 onwards (1981, 1988, 1995, 2002, 2007, and 2012) 19 Although we organize the data at the departmental level to make group sizes as comparable as possible, the population sizes still vary from around 4,000 in St. Pierre and Miquelon to about 1.8 million in the Nord department. The OST each serve as one subdivision in the

\footnotetext{
${ }^{19}$ The data were collected from the French ministry of Internal Affairs and from the www.politiquemania.com website, which provides easily accessible information about French elections at the local level. Given the large amount of information to be retrieved, it was impossible to make use of official French ministry data that are not downloadable. We did, however, compare random samples from the data we received with the official numbers and found that in every case they were exactly the same.
} 
analysis 20 There are four OST subdivisions in the east and five in the west, which in addition to the 96 departments on the mainland comprise a total of 105 such subdivisions in France. The subdivisions we refer to as "treated" are French Polynesia, Saint Pierre and Miquelon, Guadeloupe, French Guiana, and Martinique 21

In order to conduct robustness checks, we use similar data from French parliamentary elections, taken directly from the French Ministry of Internal Affairs, which are also arranged on the departmental level and span a period from 1997 to 2012. In parliamentary elections - unlike presidential elections voters elect representatives in their local constituencies, independent from the results of mainland voting. Although the overall outcome of the parliamentary elections is in most cases decided on mainland France, the uncertainty about the identity of the local MP has not yet been resolved when voters in the OST vote. Hence, if the 2005 reform has a causal effect on voting behavior in the OST to the west of mainland France, this effect should be primarily evident in presidential elections and less so in parliamentary elections. In fact we do not find any significant effect on turnout in parliamentary elections, which increases confidence that we actually identify the causal parameter of interest (see Section 5).

\subsection{Empirical Strategy}

To assess the impact of knowing the election outcome on voter turnout, we estimate equations of the following form

$$
Y_{s t}=\alpha+\eta t+\delta \mathbb{1}_{[t \geq 2005]}+\lambda \mathbb{1}_{[s \in T G]}+\beta \mathbb{1}_{[t \geq 2005]} \mathbb{1}_{[s \in T G]}+\gamma X_{s t}+\varepsilon_{s t}
$$

\footnotetext{
${ }^{20}$ For simplicity, we consider both TOMs and DOMs to be geographical units similar to French departments even if, formally, only DOMs are "departments".

${ }^{21}$ Saint Martin and Saint Barthelemy split from Guadeloupe in 2007 to become separate OST. We nevertheless count their results and population in the 2012 elections jointly with Guadeloupe to be consistent over the whole sample. The population of these two territories combined represents $8.5 \%$ of the Guadeloupe population.
} 
where $T G$ indicates the treated OST (i.e. the OST to the west of mainland France) and $Y_{s t}$ the turnout by subdivision $s$ in year $t$. $\mathbb{1}[$.$] represents the indi-$ cator function and $X$ a vector of controls; $\beta$, the coefficient on the interaction of the treatment group and the time dummy, is the difference-in-difference estimator (DID) of the causal effect of interest. As controls we use time trends, a dummy indicating second round elections and a dummy for OST.

Although splitting up the French mainland into departments helps to mitigate concerns about the differing sizes of the underlying voting populations for each observation, these differences might still be an issue in our analysis. To tackle this concern, we apply weighted least squares to equation (1) using the number of registered voters in each department as weights. Bertrand, Duflo, and Mullainathan (2004) also show that standard errors in DID frameworks that rely on long time series are susceptible to autocorrelation, which might lead to overconfidence in the precision of the point estimates. To assess the reliability of our standard error estimates, therefore, we also implement two procedures suggested to work well in this situation. First, we block bootstrap standard errors on the department level and second, we collapse the sample into a preand post-period.

Finally, we estimate specifications that allow for different trends in turnout in different geographical areas of France. Specifically, we define three geographical areas: mainland France and the eastern and western OST, which we denote by $g \in\{1,2,3\}$. We estimate separate linear and quadratic time trends for each of these territories, which is sometimes labeled as a "random trend model" (Wooldridge (2001, p. 315)) and basically boils down to a difference-indifference-in-difference type approach where previous periods are used as preprogram tests. Empirically, this approach implies that we replace $\eta t$ in equation (1) by $\eta_{g} t$ and $\eta_{g} t^{2}$. Allowing the different territories to be on different time trends over the whole sample period is an effective tool for examining whether the treatment effect we estimate in fact only captures different trajectories of turnout for the three territories. As it turns out the results are very similar to the simple DID-model. 


\section{Results}

Figure 2 illustrates the evolution of presidential election turnout averaged by year for all three territories - the mainland and the western and eastern OST 22 Here, turnout trends seem to be reasonably parallel before the legislative change, and the increase in turnout is visibly larger in the treated OST between the 2002 and 2007 elections. In 2007, however, there is a distinct increase in turnout in all parts of France, after which, the time trends again seem to follow a parallel path. Two factors could potentially have contributed to this surge. First, the 2002 election was marked by the unexpected first-round elimination of the moderate left candidate in favor of the candidate from the far right party (Section 3.3 for a discussion). This outcome led to intense public discussion on the importance of voting by those who feared the far right could do as well again. Second, the 2007 election saw two polarizing candidates: Segolene Royal and Nicolas Sarkozy, which could also have driven up turnout. Besides showing a jump in 2007 for all three territories, Figure 2 also clearly shows that turnout in the western OST increased more relative to the other territories in the west.

Table 3 displays the results of the baseline DID estimates and the random trend model (in columns (6)-(9)). In the baseline DID regressions, the point estimate is stable around 6.3 percentage points and significantly different from zero across all specifications and the standard errors are almost unaffected by clustering (columns (3) to (9)), implying that knowing the election results decreases turnout by about 6 percentage points. In columns (6) and (7) we estimate the basic random trend models and find that the point estimates increase somewhat to 9 and 11 percentage points respectively. In columns (8) and (9) we estimate the same territory-specific trend model using the size of the population in the departments as weights. Doing so again results in slight increases in the treatment coefficient to about 12 to 14 percentage points. Our preferred specification is column (9) which includes territory specific linear and quadratic time trends, a dummy indicating the election round and weighting. Here we estimate a treat-

\footnotetext{
${ }^{22}$ Hence turnout is also averaged over the two rounds by territory $g$, and year.
} 


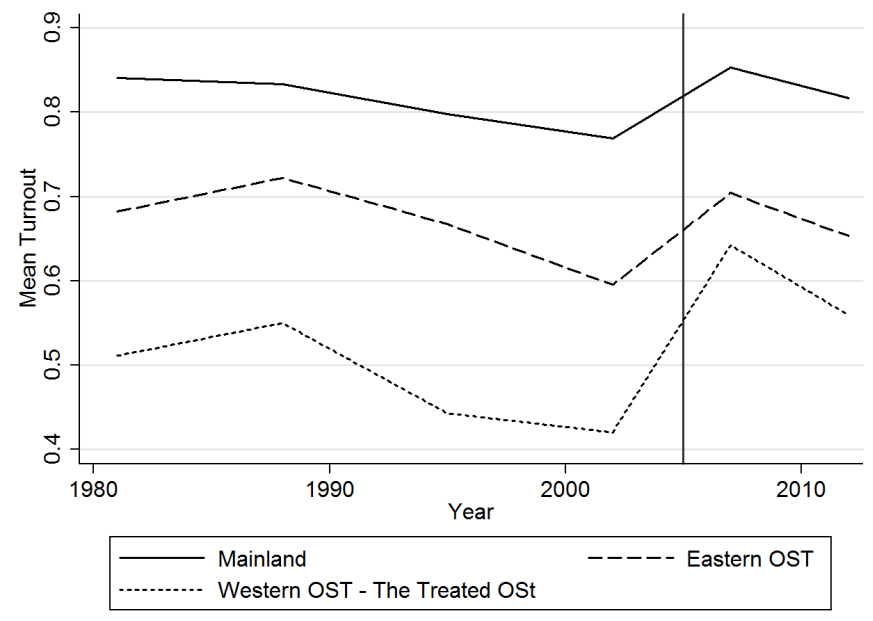

Figure 2: Average Turnout by Geographical Area and Year. The vertical line indicates the year in which the law change occurred.

ment effect of almost 12 percentage points with a robust standard error of 1.7 percentage points.

Table 4 reports additional results, including the weighted baseline DID and some efforts to assess the reliability of our standard error estimates. After we introduce weighting into the baseline DID, the point estimates indicate that not knowing the election result increases turnout by about 10 percentage points (see columns (1)-(3) in Table 4). Additionally, in columns (4) and (5) we blockbootstrap standard errors on the department level and note that they increase from slightly below 2 to about 2.7 percentage points. In the remaining columns we calculate the DID estimates on a sample that is collapsed into a pre- and post-treatment period, which produces similar point estimates of about 7 to 10 percentage points, depending on whether we weight the regression (see Bertrand, Duflo, and Mullainathan (2004)). The (clustered) standard errors are similar to the block-bootstrapped ones. In all specifications the effect is significantly different from zero 23

\footnotetext{
${ }^{23}$ We also implemented Papke and Wooldridge's (1996) quasi-maximum likelihood estimator in order to account for the fact that the dependent variable is naturally restricted to the unit
} 
In sum, in all specifications, the point estimate remains remarkably stable and quite precisely estimated. For our preferred specification, we report an increase in turnout from not knowing the election result of 12 percentage points. Moreover, concerns about autocorrelation and different population sizes underlying each observation do not seem to matter.

interval. In this approach the conditional mean of the dependent variable is specified as a logit function and the log likelihood as Bernoulli distributed. Since the Bernoulli likelihood is part of the linear exponential function family, a quasi-maximum likelihood estimator is consistent even when the Bernoulli distribution is misspecified. This result goes back to Gourieroux, Monfort, and Trognon (1984). We cluster the standard errors in all cases on the department level and find that the results are very much in line with earlier findings: not knowing the election results has a significant positive impact on turnout. 


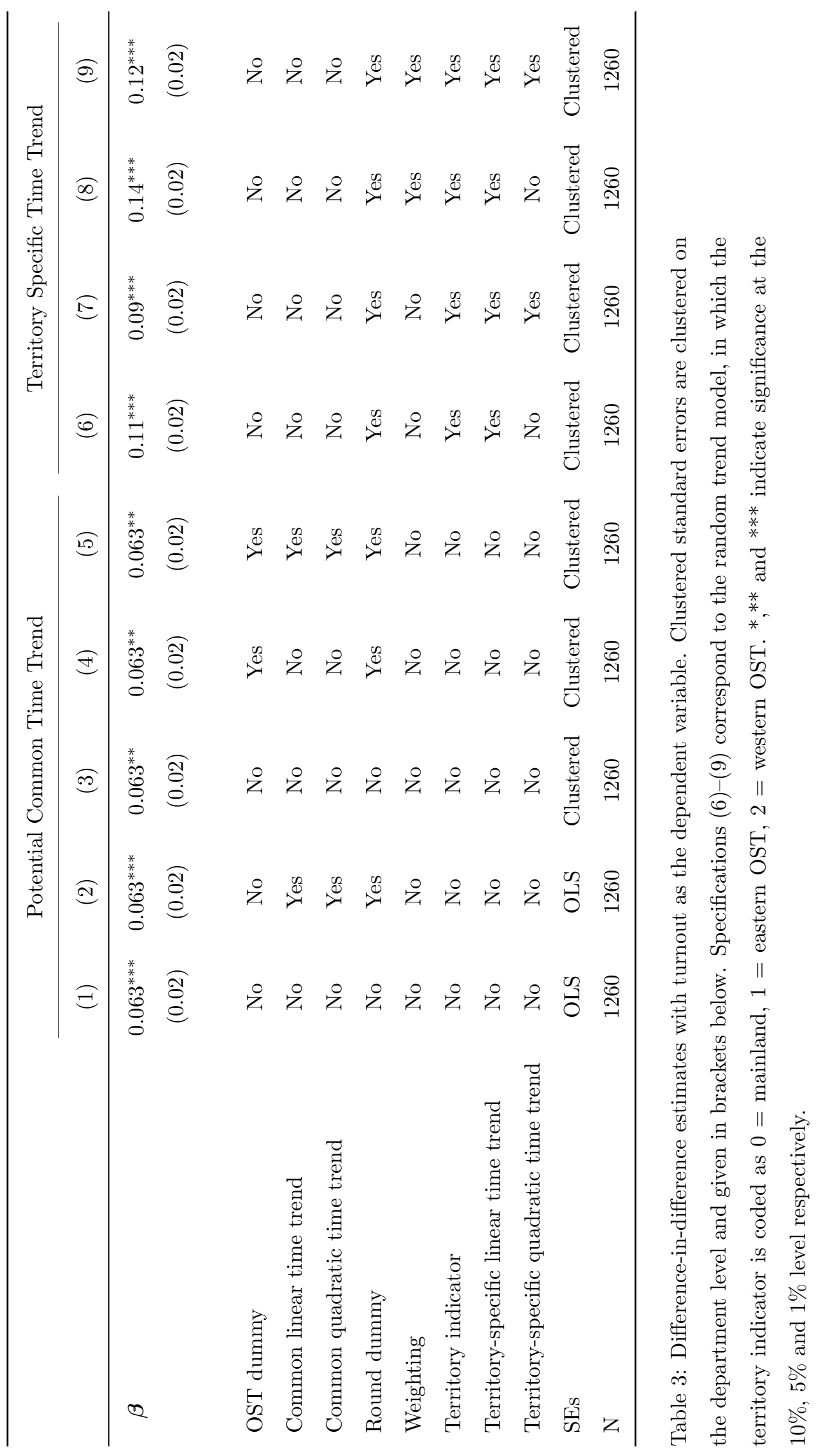




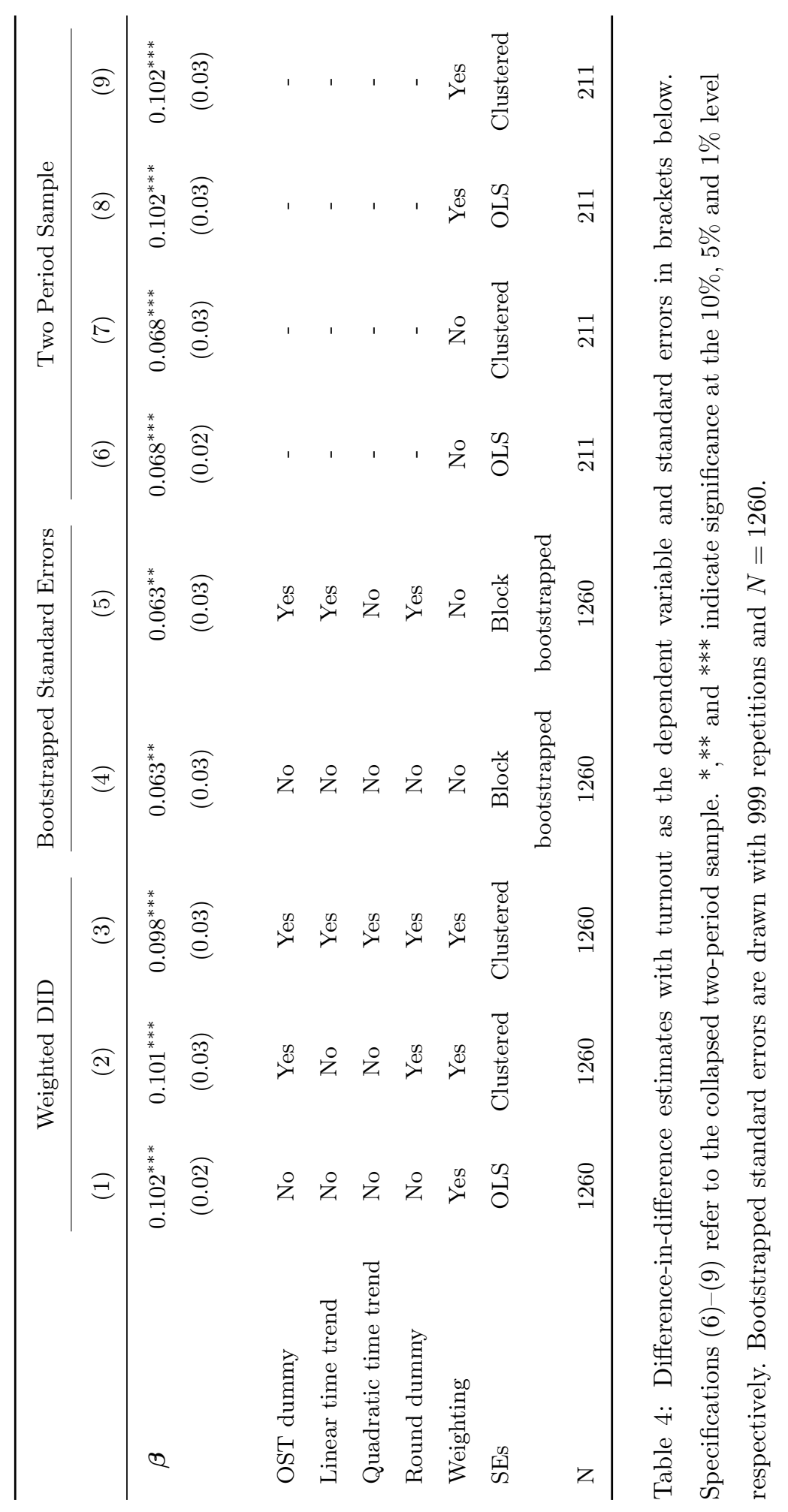




\section{Robustness Checks}

\subsection{Pseudo-estimates and the Candidate from French Guiana}

In order to check for robustness, we first calculate pseudo DID estimates using 1994 as the year in which reform was implemented (excluding post-2005 observations) $\sqrt{24}$ and secondly (falsely) using the eastern OST as a treatment group (on the full sample). In neither case do we find any significant coefficient estimate (and hence the results are not reported here).

The first-time appearance in the first round of the 2002 election of a candidate from French Guiana might have led to an overly increased turnout in this subdivision. As a consequence, our estimates might be biased since Guiana is one of the treated territories. As the 2002 election is before the 2005 reform, this bias would create a downward bias on the estimated effect of the reform on the change in turnout. Given that we observe an increase in turnout following the reform, the existence of a Guiana candidate in 2002 can only make our estimate conservative (meaning that the effect of exit poll information can only be higher than the one estimated and not lower). In any case, we control for a possible bias due to this event by including a dummy indicating Guiana in the first round of 2002. As expected, we find a positive and significant coefficient on this dummy. Nevertheless, all results from Table 3 remain literally unchanged (and are thus not reported here), indicating that this event has no impact on our estimates.

\section{2 "Le Pen Elections"}

In Section 3.3, we expressed concern that the anomalous result in the first round of 2002 - in which right-wing candidate Jean-Marie Le Pen surprisingly made it into the second round - might have impacted our results. First, we

\footnotetext{
${ }^{24}$ We prefer not to conduct this test on a sample that overlaps with 2005 since in this case the treatment effect might potentially affect the pseudo-estimate. On the other hand, we only observe four elections at two time points after the law changed. Hence it seems reasonable to split the pre-treatment period into half and run this same test on that sample.
} 
argue that this event is likely to downward bias our estimates, meaning that we are presumably estimating lower bounds of the actual effect of knowing the exit polls on turnout. Such is the case because the closeness of the election is likely to increase turnout more in the west, which on average has better information when voting, than in the eastern parts of France. As a result, the DID estimates tend to be smaller than in the counterfactual case without this highly polarizing candidate. Second, we replicate the regressions from Tables 3 and 4 excluding the first round of 2002 (see Tables 5 and 6). Reassuringly, these estimates are very much in line with those using the entire sample. In the baseline specifications, we find an increase in turnout of around $6 \%$, and as before, most controls seem to have no large effect on the results.

Once we allow for common linear and quadratic time trends, however, the effect on turnout increases slightly to about $10 \%$ (columns (6) and (7) in Table 5, and it increases even more, to about $14 \%$, when we run the regressions weighted by the number of registered voters in each department (columns (8) and (9) in the same table). The precision of our estimates also seems mostly unaffected by the smaller sample size and whether we use OLS, clustered (at the department level) or block-bootstrapped (columns (4) and (5) in Table 6) standard errors. In columns (6) to (9) of Table 6, we again use a sample that is collapsed into pre- and post- treatment periods and find similar point estimates - between $6 \%$ and $10 \%$, respectively - depending on whether or not we use weighting. Taken together, these findings strongly suggest that the results reported earlier are reliable and not biased by unusual events such as the Le Pen election. 


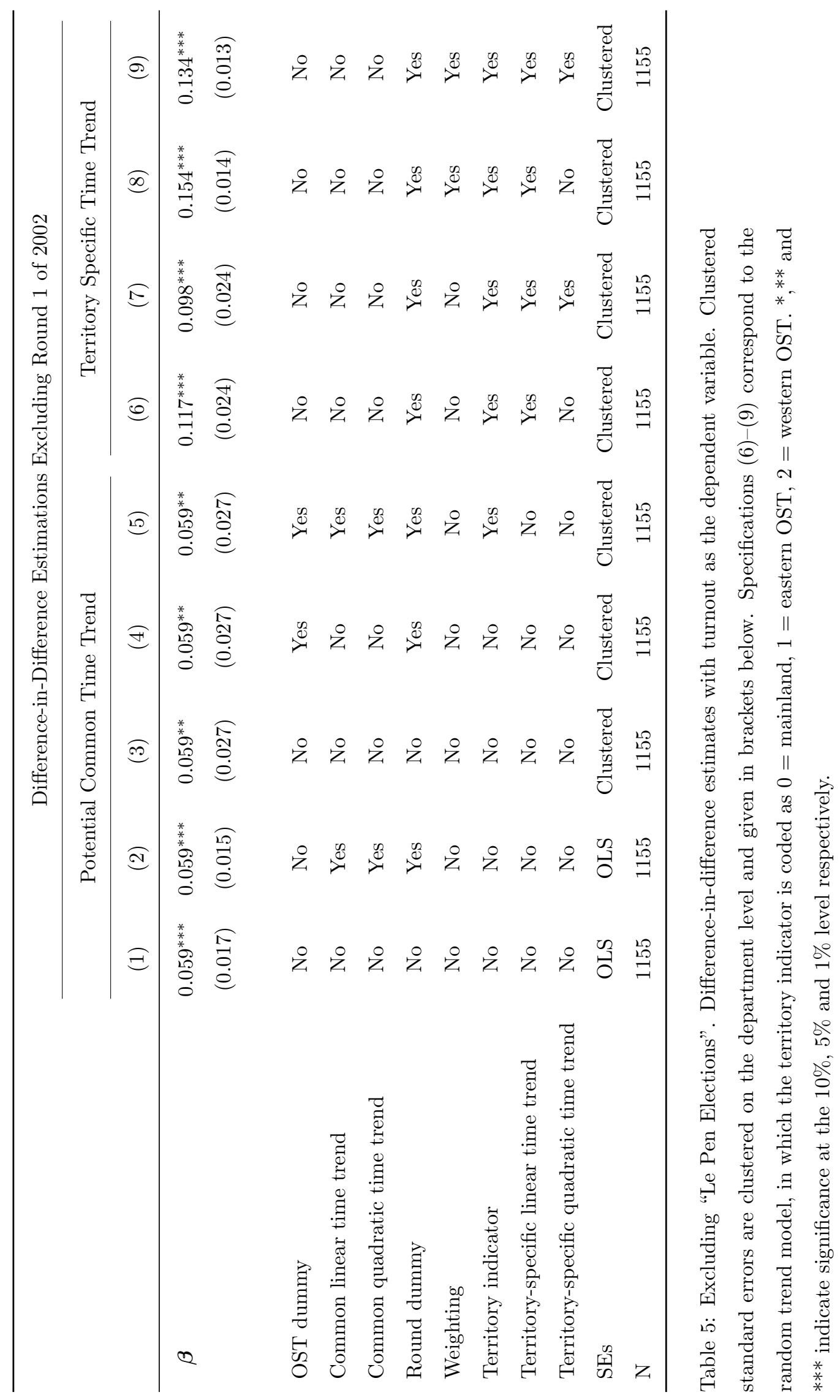

26 


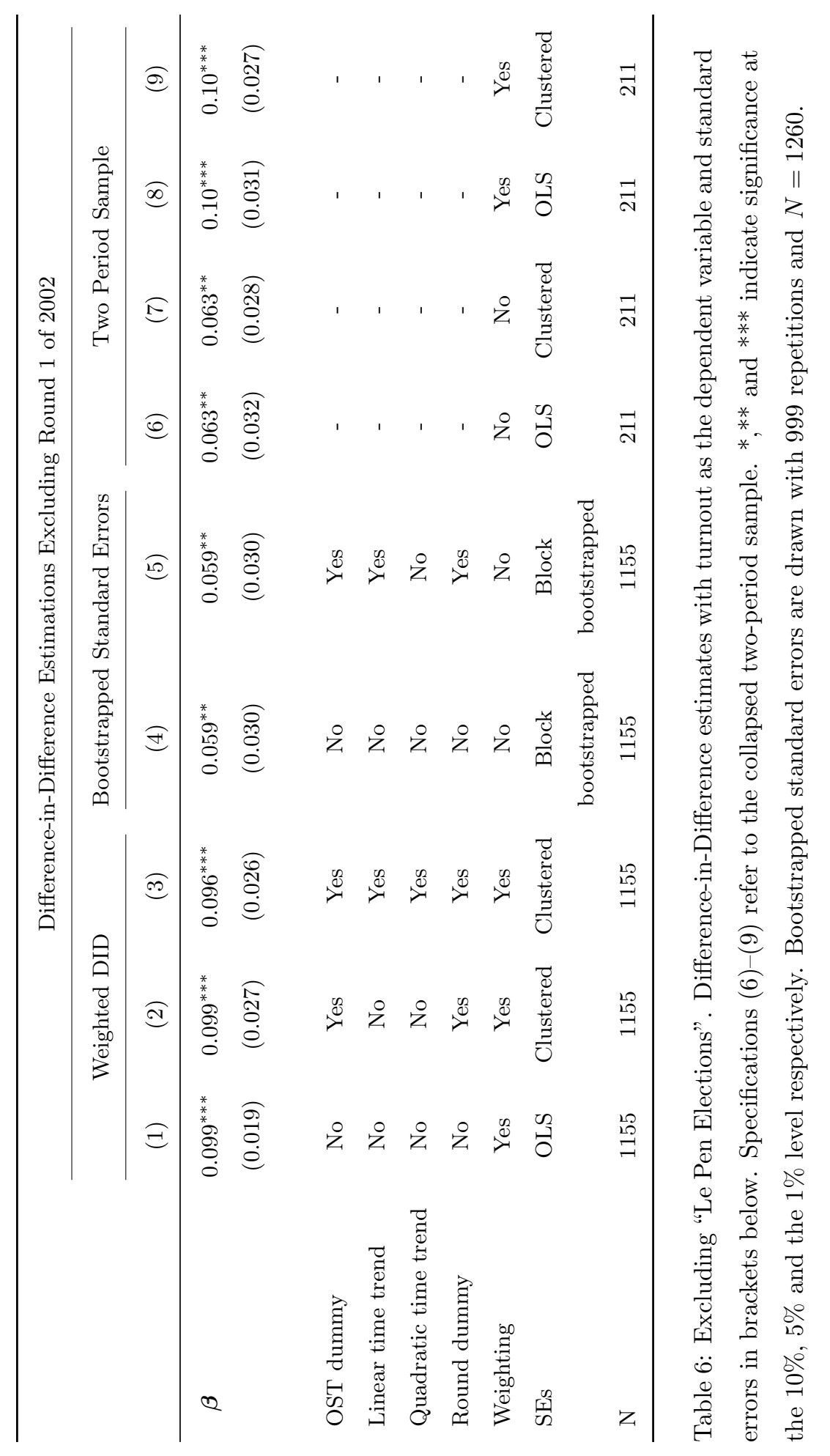




\subsection{Testing for Territory Specific Shocks on Turnout}

A threat to the validity of our difference-in-difference estimates is differing time paths for turnout in the territories versus the mainland in the absence of treatment. We can credibly test for this concern by allowing for different linear and quadratic time trends for the three territories (see Table 3). In our case, it is even possible to go one step further by using turnout data on parliamentary elections in France to re-estimate the same difference-in-difference models as in Section 3.5. Although these elections are national we would expect no treatment effect because in each subdivision voters choose between different candidates who are seeking the position as their local representative. Therefore, the result on the mainland does not influence who will represent an OST district in the national parliament ${ }^{25}$ We can therefore test for territory-specific turnout shocks that could potentially confound our estimates because such shocks, if they exist, are likely to also affect other elections. While directly testing for these concerns is essentially infeasible in DID models, our unique setting allows for this possibility.

Table 7, which summarizes the results using the parliamentary data, shows similar standard errors but much smaller coefficient estimates. Hence, given that no estimated coefficients are significantly different from zero at the $10 \%$ level and all are also much lower in absolute terms, OST-specific shocks do not seem to be a concern. This finding assures us that we are indeed identifying the causal effect of interest and not other time-variant shocks. As in Section 3.5. we also introduce weighting but again find no significant point estimates. Figure 3 summarizes the turnout trends at these parliamentary elections by territory.

\footnotetext{
${ }^{25}$ It might be the case that voters in the OST care whether their local representative is a member of a party of influence in the parliament and in that case results in the mainland may affect their voting behavior. We assume that these concerns, if they exist, are not large.
} 


\begin{tabular}{|c|c|c|c|c|c|c|}
\hline & \multicolumn{3}{|c|}{ No Common Time Trends } & \multicolumn{3}{|c|}{ Linear and Quadratic Time Trend } \\
\hline & $(1)$ & $(2)$ & $(3)$ & $(4)$ & $(5)$ & $(6)$ \\
\hline \multirow[t]{2}{*}{$\beta$} & 0.02 & 0.02 & 0.02 & 0.02 & 0.02 & 0.01 \\
\hline & $(0.02)$ & $(0.03)$ & $(0.03)$ & $(0.02)$ & $(0.03)$ & $(0.03)$ \\
\hline OST dummy & No & No & Yes & No & Yes & Yes \\
\hline Round Dummy & No & No & Yes & Yes & Yes & Yes \\
\hline Weighting & No & No & No & No & No & Yes \\
\hline SEs & OLS & Clustered & Clustered & OLS & Clustered & Clustered \\
\hline $\mathrm{N}$ & 838 & 838 & 838 & 838 & 838 & 838 \\
\hline
\end{tabular}

Table 7: Pseudo difference-in-difference estimates analogous to earlier tables before with parliamentary election turnout as the dependent variable. Standard errors are given in brackets below. The sample includes parliamentary elections from 1997 to $2012 . *, * *$ and *** indicate significance at the $10 \%, 5 \%$ and $1 \%$ level respectively. 


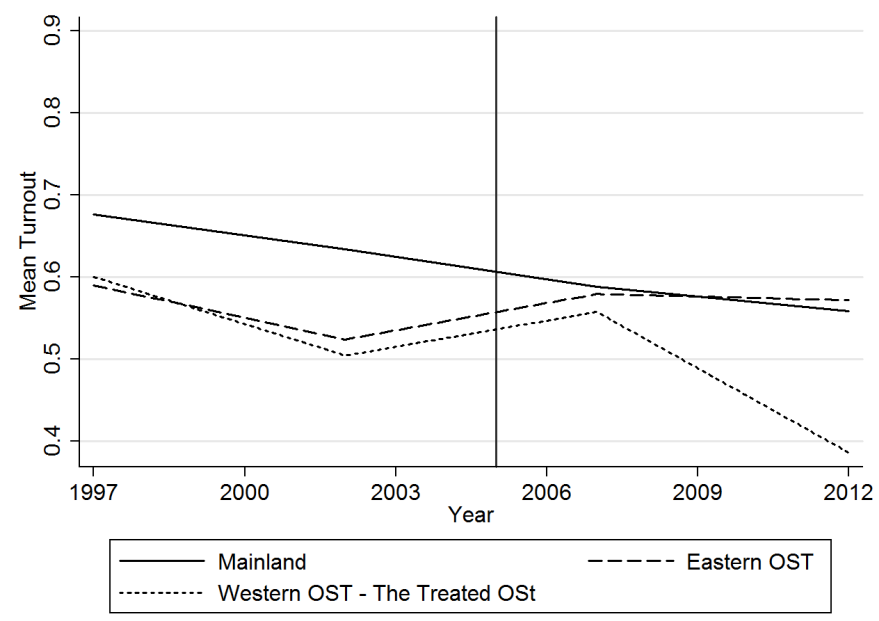

Figure 3: Average turnout by territory and year for the parliamentary elections. The vertical line indicates the year in which the law changed. No overproportional increase in turnout is apparent in the western OST.

\section{Estimating Potential Bandwagon Effects}

In political science, the "bandwagon effect" refers to the phenomena where people might vote for a candidate just because he or she is likely to win the election ${ }^{26}$ Although this effect attracted lots of attention among scholars, it turned out to be quite difficult to provide empirical evidence. An opposite effect, the "underdog" effect, where voters tend to favor the disadvantaged candidate,

\footnotetext{
${ }^{26}$ For a discussion of the psychological aspects of a bandwagon effect or impersonal influence, see, for example Kenney and Rice (1994) or Mutz (1997). Information can also affect confidence in a voting decision (Matsusaka (1995)). An electoral momentum has also been found in early presidential primaries (candidates performing well in Iowa or New Hampshire receive a future primary voter boost, as discussed in Morton and Williams (1999) and Morton and Williams (2001)). As reviewed previously, Callander (2007) provides a formal model of bandwagon voting. See also the experimental evidence of bandwagon voting in Hung and Plott (2001). Schmitt-Beck (1996) also refers to consensus heuristic. If a multitude of voters are behind one of the candidates, people take the choice of others as an indicator of political quality of the candidate.
} 
has also been discussed as a possibility ${ }^{27}$

The French natural experiment, however, provides a unique setting for examining such effects in that prior to the 2005 reform, voters in the western OST knew the winner when they went to the polls. Our identification strategy thus relies on estimating the impact of the leading presidential candidate's voting edge, as compared to that of the runner-up on the mainland (and in the eastern OST), on the vote difference in the western OST. To determine this impact, we estimate the following equation

$$
\Delta_{s, t}=\alpha+\beta \Delta_{\text {mainland }, t}+\gamma \mathbb{1}_{[t>2005]}+\delta \Delta_{\text {mainland }, t} * \mathbb{1}_{[t>2005]}+\varepsilon_{s, t},
$$

where $\Delta_{\text {mainland, } t} \in[0,1]$ is the normalized difference of votes between the candidate with the most votes and the runner-up at time $t$ on the mainland (and in the eastern OST) and $\Delta_{s, t} \in[-1,1]$ is the same difference in the western departments at time $t$. We use only the vote difference in the western OST as the left-hand variable in this estimation since the non-treated departments contribute to $\Delta_{\text {mainland,t }}$. Our approach minimizes endogeneity concerns because the regressors are predetermined. $\mathbb{1}_{[.]}$once again denotes the indicator function. Essentially, equation (2) estimates a pre- and post-2005 slope, in which the parameter of interest, $\delta$, indicates the difference between both coefficients. This approach allows us to test for a bandwagon effect using simple t-tests on $\delta$. If such an effect exists, we would expect $\delta$ to be significantly different from zero. A negative $\delta$ would indicate that the results in west OSTs are less correlated with mainland results after the reform (without exit poll information) than before the reform (with exit poll information). Thus a negative parameter indicates a bandwagon effect, where voters in western OST tended to follow the announced mainland results before the reform. On the contrary, a positive $\delta$ indicates an underdog effect with western OST voters voting less for the mainland favourite

\footnotetext{
${ }^{27}$ West $(1991$, p.153) discusses the case of Walter Mondale and Gary Hart in the 1984 US presidential nominating process to illustrate the underdog effect. Mondale had a lead over Hart. Hart then applied the strategy of "do not let the powerbrokers tell you the race is over." This strategy helped Hart to attract substantial amount of voter support, losing at the end but performing much better than anticipated.
} 
before the reform than after.

Our estimates are summarized in Table 8. We estimate equation (2) via OLS and find a pre- treatment slope coefficient of 1.17 , which is statistically significant different from zero at the $1 \%$ level. We also find a large negative slope coefficient of -4.05 for the post-2005 period. The difference $\delta$ between both coefficients is therefore negative $(-5.22)$ and statistically significant at the $10 \%$ level using ordinary clustered, and bootstrapped standard error estimates (middle of Table 8) in the t-test. We also conduct a test of the equality of the pre- and post-2005 slope coefficients (bottom of Table 8), which rejects equality at the $1 \%$ level. Both coefficients, when taken alone, are statistically different from zero, indicating that the positive relation when voters know who will win turns negative after the law changes.

We also estimate the same equation excluding observations where the vote edge from the mainland was larger than 20 percentage points (first round of 1988 and second round of 2002). Visual inspection of the raw data suggests that these observations could be driving our estimates. Nevertheless, the last column of Table 8 shows that such outlier observations are not a problem. The point estimates and standard errors increase somewhat but all estimates are still significant in all cases. Figure 4 , which plots the fitted and raw $\Delta_{\text {treated,st }}$ versus $\Delta_{\text {mainland, } t}$ relation separately before and after 2005, confirms this conclusion graphically.

Overall, these results clearly suggest that election results in western OSTs were more positively correlated with the mainland results before the reform when western OST voters could find out the winner in mainland results before voting. In practice, the candidate ahead in mainland France was more likely to win in western OSTs before the reform (when voters had access to information on the identity of the leader on the mainland) than after the reform (when voters no longer had access to such information). To our knowledge, the evidence we have provided is the best from the field so far which demonstrates the existence of a bandwagon effect. 


\begin{tabular}{|c|c|c|}
\hline & Full Sample & Excluding Outliers \\
\hline \multirow[t]{2}{*}{ Pre-2005 slope estimate } & $1.18^{* * *}$ & 7.45 \\
\hline & $(0.29)$ & $(4.71)$ \\
\hline \multirow[t]{2}{*}{ Post-2005 slope estimate } & $-4.04^{*}$ & -4.04 \\
\hline & $(2.89)$ & $(3.07)$ \\
\hline Difference $\delta$ & -5.22 & -11.49 \\
\hline \multicolumn{3}{|l|}{ Corresponding standard errors: } \\
\hline OLS & $(2.91)^{*}$ & $(5.62)^{* *}$ \\
\hline Clustered by department & $(2.04)^{*}$ & $(3.78)^{* *}$ \\
\hline Bootstrapped & $(1.23)^{* * *}$ & $(5.76)^{* *}$ \\
\hline Block bootstrapped by department & $(1.73)^{* * *}$ & $(3.31)^{* * *}$ \\
\hline$\chi^{2}$ test of equality & $\chi^{2}=16.57^{* * *}$ & $\chi^{2}=3.74^{*}$ \\
\hline $\mathrm{P}$ value & $<0.01$ & 0.053 \\
\hline $\mathrm{N}$ & 60 & 50 \\
\hline
\end{tabular}

Table 8: Estimating equation (2) with $\Delta_{\text {treated,st }}$ as the dependent variable. Several standard error estimates are given for the t-test of $H_{0}$ : the difference in pre- and post-2005 slopes is zero. ${ }^{*}, * *$ and $* * *$ indicate significance for this t-test at the $10 \%, 5 \%$ and $1 \%$ level, respectively. 


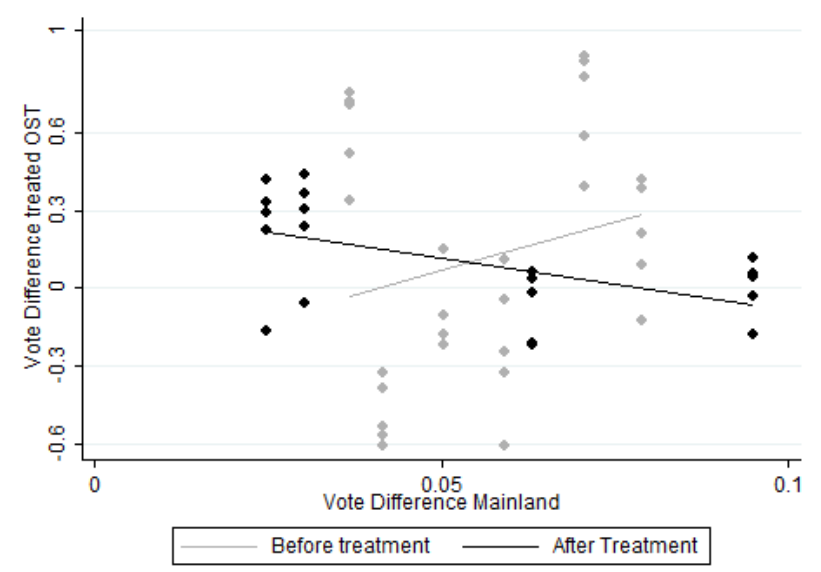

Figure 4: Plot of $\Delta_{\text {mainland }}$ versus $\Delta_{\text {treated }}$, separately before and after 2005 for the sample without outliers. The former exhibits a clear positive trend and the latter a distinct negative one indicating, that, ceteris paribus, the leading candidate on the mainland loses votes when these voters have no exit poll information from the mainland.

\section{Concluding Remarks}

The advent and proliferation of new electronic information sources and social media has had profound impacts on many aspects of politics across the globe. Increasingly, individuals are able to us the web to coordinate protests against governments and other groups, acquire secret and classified information, and to monitor exit poll results while an election is still in process. In this paper we investigate the possible effects of the last development on political behavior. Previous research using naturally occurring elections has suffered from a number of methodological problems in identifying whether such information can have a causal effect on voting behavior.

We take advantage of a unique natural experiment from 2005, in which French citizens from overseas territories to the west of mainland France began for the first time to vote without knowing the choices made by mainland voters. We find that knowing the outcome of early voting decreases turnout by about 12 
percentage points in our preferred specification. We also find empirical support for bandwagon voting in which later voters, if they participate, are more likely to vote for the expected winner.

Our results suggest that when voters can access exit poll results during an election voting behavior is significantly affected. These effects on voting behavior (lower participation and a bandwagon effect) provide advantages to candidates and political parties favored by early voters, which do not exist in the absence of the information. If later voters differ from early voters in terms of demographics and ideological preferences, then we would also expect such information to have an effect on the types of public policies chosen by elected officials as well. Candidates and political parties, moreover, have an incentive to manipulate the timing of voting and the type and accuracy of information revealed through exit polls. Concerns about the effects of exit polls on elections as expressed by many government officials, candidates, and party leaders and calls for restrictions on such information are thus strongly supported by our results.

\section{References}

BALE, T. (2002): "Restricting the broadcast and publication of pre-election and exit polls: some selected examples," Representation, 39(1), 15-22.

Battaglini, M. (2005): "Sequential voting with abstention," Games and Economic Behavior, 51(2), 445 - 463.

Battaglini, M., R. Morton, and T. Palfrey (2007): "Efficiency, equity, and timing of voting mechanisms," American Political Science Review, 101(03), 409-424.

Bertrand, M., E. Duflo, and S. Mullainathan (2004): "How Much Should We Trust Differences-In-Differences Estimates?," Quarterly Journal of Economics, 119(1), 249-275. 
Best, S., and B. Krueger (2012): Exit Polls: Surveying the American Electorate, 1927-2010. CQ Press.

Callander, S. (2007): "Bandwagons and momentum in sequential voting," Review of Economic Studies, 74(3), 653 - 684.

CARPINI, M. (1984): "Scooping the voters? The consequences of the networks early call of the 1980 presidential race," Journal of Politics, 46(3), 866-885.

Carter, R. (2009): "German politicians livid at Twitter vote leak," Agence France Presse - English.

Dubois, P. (1983): "Election night projections and voter turnout in the west: A Note on the Hazards of Aggregate Data Analysis," American Politics Research, 11(3), 349-364.

Gourieroux, C., A. Monfort, and A. Trognon (1984): "Pseudo Maximum Likelihood Methods: Theory," Econometrica, 52(3), pp. $681-700$.

Hung, A. A., And C. R. Plott (2001): "Information Cascades: Replication and an Extension to Majority Rule and Conformity-Rewarding Institutions," American Economic Review, 91(5), pp. 1508 - 1520.

JACKSON, J. (1983): "Election night reporting and voter turnout," American Journal of Political Science, 27(4), 615 - 635.

Kenney, P., And T. Rice (1994): "The psychology of political momentum," Political Research Quarterly, 47(4), 923-938.

Leonardo, S. (1983): "Restricting the Broadcast of Election-Day Projections: A Justifiable Protection of the Right to Vote," University of Dayton Law Review, 9, 297.

MAtsusakA, J. (1995): "Explaining voter turnout patterns: An information theory," Public Choice, 84(1), 91-117. 
McAllister, I., And D. Studlar (1991): "Bandwagon, underdog, or projection? Opinion polls and electoral choice in Britain, 1979-1987," Journal of Politics, 53(3), 720-741.

Morton, R., and K. Williams (1999): "Information asymmetries and simultaneous versus sequential voting," American Political Science Review, 93(1), $51-67$.

Morton, R., and K. Williams (2001): Learning by voting: Sequential choices in presidential primaries and other elections. University of Michigan Press.

Mutz, D. (1997): "Mechanisms of momentum: does thinking make it so?," Journal of Politics, 59(1), 104-125.

PAPke, L., And J. Wooldridge (1996): "Econometric Methods for Fractional Response Variables with an Application to 401 (K) Plan Participation Rates," Journal of Applied Econometrics, 11, 619-632.

SAYare, S. (2012): "French Media Question Election Reporting Rules," New York Times.

Schmitt-Beck, R. (1996): "Mass media, the electorate, and the bandwagon. A study of communication effects on vote choice in Germany," International Journal of Public Opinion Research, 8(3), 266-291.

Spangenberg, F. (2003): "The freedom to publish opinion poll results: Report on a worldwide update," Amsterdam: Foundation for Information.

Sudman, S. (1986): "Do exit polls influence voting behavior?," Public Opinion Quarterly, 50(3), 331-339.

Thompson, D. (2004): "Election time: normative implications of temporal properties of the electoral process in the United States," American Political Science Review, 98(01), 51-63.

Tuchman, S., And T. Coffin (1971): "The influence of election night television broadcasts in a close election," Public Opinion Quarterly, 35(3), 315-326. 
West, D. (1991): "Polling effects in election campaigns," Political Behavior, 13(2), 151-163.

WoOlDRIDGE, J. (2001): Econometric analysis of cross section and panel data. MIT press. 